\title{
Neurobiology and crime: A neuro-ethical perspective
}

\author{
Farah Focquaert \\ Department of Philosophy and Moral Sciences, Bioethics Institute Ghent, Ghent University, Blandijnberg 2, 9000 Gent, Belgium
}

\section{A R T I C L E I N F O}

\section{Keywords:}

Neuro-ethics

Ethics

Neurocriminology

Neurobiology

Rehabilitation

Forensic psychiatry

\begin{abstract}
A B S T R A C T
Current neurobiological research in the field of criminology focuses on the neurobiological characteristics associated with antisocial behavior, the prediction of antisocial behavior later in life based on neurobiological risk factors, and the ways in which neurobiological factors interact with psychological and environmental risk factors. Although the use of neurobiological knowledge has the potential to make several criminal justice practices more objective and humane, it may involve practices that are challenging with respect to stigma, neuro-determinism, autonomy and mental liberty. Four main areas of interest can be identified where neurobiology plays or could play a role: (1) criminological research focused on understanding criminal behavior, (2) the (early) detection/prediction of and intervention in deviant behavior, (3) criminal proceedings: to assess responsibility and inform sentencing, and (4) forensic rehabilitation and treatment settings. In this paper, I discuss the main ethical dilemmas that arise when considering the use of recent neurobiological advances in these areas.
\end{abstract}

\section{Introduction}

Decades of research on criminal behavior has shown that a multitude of environmental factors contribute to criminal behavior (Caruso, 2017). In addition, a growing body of research shows that, on average, individuals who engage in deviant behavior demonstrate differences in brain structure and functioning (Glenn, Raine, \& Schug, 2009; Yang \& Raine, 2009) and hormone and neurotransmitter levels (Glenn, Schug, Gao, \& Granger, 2011; O'Leary, Taylor, \& Eckel, 2010). Behavioral genetics studies also indicate that about $40-60 \%$ of the variance in criminal behavior is due to genetic influences (Raine, 2013). Moreover, these environmental and biological factors that increase an individual's risk for criminal behavior are highly connected. Biological predispositions influence the ways in which individuals react to the environment. In turn, environmental factors can affect gene expression, hormone and neurotransmitter levels, and ultimately brain structure and functioning.

Current neurobiological research in the field of criminology focuses on the neurobiological characteristics associated with antisocial behavior (e.g., reduced physiological arousal, poor frontal brain functioning, reduced volume in the amygdala, hormonal deficits and genetic risk factors), the prediction of antisocial behavior later in life based on neurobiological risk factors (e.g., low resting heart rate, poor fear conditioning, increased testosterone levels, attenuated heart rate response to stress, reduced amygdala volume, low activity in the anterior cingulate cortex), and the ways in which neurobiological risk factors interact with psychological and environmental risk factors (Cornet, 2015: Glenn, Focquaert, \& Raine, 2015).
Identifying neurobiological risk factors for criminal behavior does not imply that criminal behavior is "hard-wired" in the brain or that some individuals are irreversibly destined for a life of crime. All behavior, not just deviant behavior, is caused by a complex interplay between our neurobiology (genes, brain, hormones, etc.), psychology (cognitive-emotional mechanisms such as empathy, inhibition, selfcontrol or the lack thereof) and the environment (e.g., peers, socioeconomic status, access to healthcare, education). There is no one-to one relationship between biological factors and crime. Many individuals with biological risk factors will not go on to commit crimes and some individuals who do not exhibit a specific risk factor may proceed to commit a crime (Glenn et al., 2015). A wide range of biological, psychological and environmental factors, and the interactions between them, may contribute to the risk for antisocial behavior. For example, the neurodevelopment of brain regions (e.g., anterior cingulate cortex, prefrontal cortex) involved in attentional control, inhibition, executive functioning and self-regulation can be compromised if children grow up in impoverished conditions.

"The chaotic and impoverished background of most offenders is unlikely to offer the neurological prerequisites desired to foster cognitive, behavioural and interpersonal competencies. Sufficient nutrition, rest, a stimulating and loving environment; ample opportunity to observe prosocial behaviour; consistent rewards for the incremental development of self-regulation and empathy for others; a childhood free from physical violence and access to toxic substances; are not the typical context of the child more likely to become an offender. These prerequisites of emotion regulation, impulse control and empathy are

E-mail address: farah.focquaert@ugent.be. 
often sadly lacking" (Nee \& Vernham, 2017).

The environment plays an important role in shaping brain development and functioning, and due to ongoing brain plasticity, significant changes may occur in adulthood as well. Studies suggest that cognitiveemotional training can improve cognitive, emotional and interpersonal competencies in children and adults (Cornet, de Kogel, Nijman, Raine, \& van der Laan, 2015; Felmingham et al., 2007; Paquette et al., 2003; Ruedo, Posner, \& Rothbart, 2005).

Clinical guidelines support behavioral programs (e.g., parenting programs and psycho-social interventions) as first-line treatment options for aggressive behavior problems in children and adolescents (Scotto Rosato et al., 2012). A recent review study (Balia, Carucci, Coghill, \& Zuddas, 2017) concluded that their findings partially support adding pharmacotherapy (e.g., stimulant medications and atypical antipsychotics) as a potentially useful therapeutic approach for aggressive behavior in children with conduct disorder who do not respond to psycho-educational or psychological interventions. However, they also report that there is very little good-quality evidence to support the efficacy, effectiveness and safety of pharmacological treatments for aggression in conduct disorder. At present, researchers are looking for molecular and neurobiological targets for pharmacological development that may provide greater control over self-regulation and aggressive behavior (Asherson \& Cormand, 2016).

Non-invasive neuro-biological interventions may have the potential to ameliorate current approaches to rehabilitation and treatment of deviant behavior. Although a lot more research is needed, preliminary research studies suggest that various non-invasive neuro-interventions can ameliorate cognitive-emotional difficulties (e.g., impulsivity, disinhibition, attention deficits, aggressive tendencies, addictive tendencies) by indirectly or directly rewiring the brain. Neuro-interventions such as vitamin and omega 3 supplementation, cognitive-emotional training using computer tasks, EEG neurofeedback or real-time fMRI biofeedback, and transcranial direct current stimulation may be used to help prevent future deviant behavior in at-risk children, adolescents and adults (e.g., Batista, Klaus, Fregni, Nitsche, \& Nakamura-Palacios, 2015; Dadds, Cauchi, Wimalaweera, \& Brennan, 2012; Dambacher et al., 2015; Dean, Bor, Adam, Bowling, \& Bellgrove, 2014; Konicar et al., 2015; Micoulaud-Franchi et al., 2014; Raine, Portnoy, Liu, Mahoomed, \& Hibbeln, 2015; Sitaram et al., 2014; Soff, Sotnikova, Christiansen, Becker, \& Siniatchkin, 2017).

The use of neurobiological knowledge, measures and techniques has the potential to make several criminal justice practices more objective and humane. However, it may equally lead to the moral acceptance of practices that are deemed controversial. In general, worries arise about the difficulty to consistently define the scope and characteristics of complex behaviors such as violence and aggression and to develop reliable measures of such traits (Farahany, 2016; Sadler, 2013; Specker, Focquaert, Sterckx, \& Schermer, 2017). Concepts such as deviance, violence and aggression are normative concepts and run the risk of over-including normal variations in behavior as deviant or wrong behavior due to societal, religious or other cultural preferences. The risk of false positives inherent to medical diagnoses in general and to psychiatric diagnoses in particular urges us to be very careful (Glenn et al., 2015; Wakefield, 2016).

When mental health patterns become dysfunctional, clinical psychiatric diagnoses are warranted and needed. However, scientific studies do not back the categorization of mental health problems within well-defined and well-delineated pathologies or the identification of DSM or ICD10 disorders in terms of biological natural kinds. Complex mental health problems are linked to polygenetic gene profiles, diverse neurobiological underpinnings, and complex environmental influences, and they reflect varying degrees of dysfunction. Most complex mental health problems involve extremes of normal cognitive-emotional traits and behavior that exist on a continuum in the normal population (Livesly, 2012; Widiger, 2011). If we combine these concerns with the risk of stigmatization and 'neuro-determinism', the need for caution and adequate safeguards becomes paramount: "Techniques for monitoring and manipulating brain functions are developing rapidly. Prudence and restraint in their application seem advisable" (Fuchs, 2006, 605; Specker et al., 2017).

In this paper, I discuss some of the main ethical dilemmas that arise when considering the use of recent neurobiological advances to address antisocial, violent behavior. Overall, four areas of interest can be identified where neurobiology plays or could play a role: (1) criminological research focused on understanding criminal behavior, (2) the (early) detection/prediction of and intervention in deviant behavior, (3) criminal proceedings: to assess responsibility and inform sentencing, (4) forensic rehabilitation and treatment settings. These areas of interest face important ethical challenges with respect to stigma, neurodeterminism, autonomy and mental liberty.

\section{Discussion}

\subsection{Criminological research}

One of the most exciting areas where neurobiological measures and data are useful is the field of criminological research. Thus far, research on human aggression has largely focused on the societal causes of violent behavior and relatively little on the underlying neurobiological basis (Asherson \& Cormand, 2016). If we want to increase our understanding of criminal behavior and develop better criminological theories, then we need to incorporate the neurobiological influences on antisocial behavior. As mentioned, all behavior is caused by a complex interplay between our neurobiology, neuropsychology and the environment. If we limit criminological research to the behavioral and environmental aspects underlying criminal behavior, this will provide only a partial understanding of what drives an individual to commit crimes. In fact, recent studies provide considerable evidence for physiological, hormonal, neuroanatomical, neuro-functional, and genetic risk factors for crime (Cornet, 2015).

A lot more research is needed to fine-tune our understanding of the biological risk factors for crime and a lot is to be gained from such knowledge. For example, in the US, developmental brain science has been used to argue against capital punishment and life imprisonment for juveniles due to not fully developed brain areas in the frontal cortex making it harder for adolescents to resist deviant behavior and more likely for them to indulge in risky behaviors (Cohen \& Casey, 2014; Steinberg, 2013). Neurobiological and neuropsychological measures can (potentially) be used in criminal justice settings as additional means to understand and predict criminal behavior, to inform forensic psychiatric reports, to assess competency to stand trial, to substantiate the reliability of statements of witnesses, victims or defendants, and to ameliorate forensic mental health treatment (Chandler, 2016; de Kogel \& Westgeest, 2015; Meynen, 2013a; Roskies, Schweitzer, \& Saks, 2013). For example, such measures can reveal brain tumors (e.g., in case of acquired pedophilia), identify structural and functional brain abnormalities (e.g., in case of fronto-temporal dementia, traumatic brain injury, abnormalities linked to schizophrenia), and in the future potentially inform recidivism risk (e.g., as suggested by preliminary studies linking brain abnormalities to future crime) (Aharoni et al., 2014; Brown \& Murphy, 2010; Elman, Borsook, \& Volkow, 2013; Farah, Hutchinson, Phelps, \& Wagner, 2014; Moriarty, 2008; Volkow \& Baler, 2014).

Neurobiological measures provide new and often challenging ways to identify antisocial and psychopathic personality disorders, and to expand criminal profiling and behavioral prediction. Research in the field of neurocriminology investigates which neurobiological features are associated with antisocial behavior in order to better understand, intervene in and predict criminal behavior (Cornet, 2015; Glenn \& Raine, 2014; Sirgiovanni, Corbellini, \& Caporale, 2016). A lot of this research focuses on at-risk youth and includes benign research interventions such as measuring heart rate or skin conductance, taking 
hormonal measures from saliva, neuropsychological paper-pencil and/ or computer tasks, or behavioral training programs for emotion recognition. Other research focuses on parent-infant dyads and how the development of the physiological stress-system and social behavior interact and are affected by parent-infant bonding (for a review, see Cornet et al., 2015). The current research field aims to integrate neurobiological, psychological and environmental risk factors for crime, and highlights the importance of a multi-factorial approach to criminal behavior. It is rightfully argued that "complementing traditional criminological measures with neurobiological methods potentially strengthens the empirical validity of criminological theories" (Cornet, 2015, 6).

Notwithstanding the huge benefits such neurobiological knowledge could entail, a sufficiently nuanced approach may be lost when neurobiological knowledge is reflected on in the wider academic debate and the wider public debate. Our growing knowledge on the neurobiological correlates of criminal behavior, in combination with the political and societal desire for quick fixes when it comes to aggressive, criminal behavior, may result in the mistaken view that antisocial behavior or antisocial personality disorders can be reduced to abnormalities in the brain or genes of a given individual. This may further lead to false hopes about neurobiological interventions as 'cures' or 'quick fixes' for criminal behavior. Such a worrisome trend can be seen in the current academic debate on neuro-interventions for criminal behavior, as well as in the public debate (see, Specker, Focquaert, Raus, Sterckx, \& Schermer, 2014).

False views on neuro-determinism neglect the importance of nonbiological risk factors such as socio-economic and peer-related risk factors, and psychological concepts such as self-control, agency and motivation in trying to address recurrent deviant behavior. By merely or overly focusing on the biological mechanisms involved in deviant behavior, we may also neglect or underestimate the need for cognitive behavioral therapy, skills training and other kinds of support (e.g., education, housing, employment) in trying to lead a crime-free life.

Researchers in the field of neuro-criminology have the very important role of explaining and communicating their research findings in the most nuanced way possible. It is pivotal to continuously identify the limits of their research findings in their published research to avoid misinterpretation and misuse. There is a need to communicate such research findings to the wider public in a more detailed and careful manner. This responsibility confers on researchers and journalists alike.

Scientific researchers are bound by the applicable ethical standards of research on humans provided by the World Medical Association (Declaration of Helsinki, 2013), the Council of Europe (Oviedo Convention, 1997), the World Health Organization and the Council for International Organizations of Medical Sciences (International Ethical Guidelines for Biomedical Research involving Human Subjects, 2002; International Ethical Guidelines for Epidemiological Studies, 2009), and other relevant institutions, as implemented by national law. Research involving humans needs to pass a REC (Research Ethics Committee) or IRB (Institutional Review Board) to check if the applicable guidelines are adequately taken into account. These minimum demands need to be respected within all research, including criminological research. This manuscript does not focus on the established guidelines, but discusses subtle and potentially underestimated ethical challenges with respect to the use of neuro-tools and neuro-interventions.

\subsection{Deviant behavior: (early) detection, prediction and intervention using neurobiology}

While a lot of hope is vested in the detection of neurobiological risk and protective factors and in the implementation of prevention measures for antisocial and criminal behavior, we need to bear in mind that practices of detection, prediction and prevention may unintentionally result in undesirable ethical, social and legal consequences or be deliberately misused for social control purposes (Hörskotter, Berghmans,
\& de Wert, 2014; Specker et al., 2017). For example, such undesirable consequences may result from labeling individuals who have never committed a (violent) crime but may be more likely to commit crimes once identified as at risk. What can be easily forgotten within a criminal justice approach focused on safety and prevention is that we are dealing with unique individuals in complex environmental settings whose behavior is not reducible to mere neurobiological profiles. Moreover, receiving a psychiatric label, especially when tied to a neurobiological profile, may prevent successful treatment outcomes or successful behavior change in the long run due to prejudice and discrimination, stigmatization, fear of rejection and mistreatment, low self-esteem and self-blame. Rather than lowering the risk of future deviant behavior, neurobiological profiling may be counterproductive and increase the risk of future deviant behavior (Glenn et al., 2015). Similar worries have been voiced by Fuchs (2006): "The possible benefit of predictive imaging would have to be carefully weighed not only against possible harm but also against the burden of knowledge and the possible discriminations caused by being an at-risk patient" (601).

Concerns about labelling, stigma and unnecessary interventions are especially important when thinking of early detection and prevention of deviant behavior in children and adolescents. While early intervention may be beneficial, especially in children with callous-unemotional traits, it is important to recognize that early intervention in childhood and adolescence can be detrimental due to the negative effects of labelling children who are biologically 'at-risk' (e.g., exhibit neurobiological markers of reduced emotionality and reduced sensitivity to punishment) as 'bad' children. Although early screening and intervention may benefit some children who are at risk of exhibiting violent, anti-social behaviors, there is a substantial risk of increasing anxiety, stigma and falling prey to unnecessary interventions. The stigmatization, internalization and self-blame that results from such labels may subsequently stimulate the development of maladaptive cognitions and narratives (Glenn et al., 2015; Specker et al., 2017).

Glenn et al. (2015) have previously identified three areas of ethical concern related to potential screening policies for mental disorders: (1) the efficacy, cost-effectiveness, and likely 'false alarm' rate of population-based screening strategies, (2) anxiety and stigma, and (3) informed consent and the obligations between parents and children. I will briefly apply these concerns to the early detection of biological risk factors for deviant behavior.

(1) Population-wide screening for biological markers (e.g., in all children at a certain age) is only justifiable if an efficacious and costeffective intervention exists to prevent the development of the behavior in children who are identified as at-risk. We do not know whether it is more cost-effective to treat those children who already engaged in violent, anti-social behavior rather than preventively screening all children. Moreover, even if we have or will have efficacious, cost-effective interventions available, it is unclear if knowledge about genetic or biological risk-factors will motivate parents to seek help. In fact, even if treatment is sought, the screening results might undermine the parents' hopes to effectively prevent such behavior in their child(ren). Furthermore, where do we draw the line between high risk and low risk and how do we determine if a child is at-risk? The answer to these questions involves a normative judgment that will inevitably leave out children who could also have benefited from preventive treatment either because they fall just outside the at-risk cut-off line or because of false negatives inherent to population-wide screening and intervention strategies. Similarly, false positives will lead to unnecessary interventions that may be considered harmful to the child in question (Holm, 2007). For these reasons, and the ethical demand to address social inequities, screening and intervention strategies for biological risk-factors in childhood and adolescence should never substitute the implementation of prevention policies that reduce exposure to known common risk factors involved in the 
development of criminal behavior (e.g., prenatal and school-based nutrition programs, programs against child abuse and maltreatment, etc.).

(2) It has been argued that genetic or biological screening and early intervention is only justifiable (a) for disorders with a high genetic determination, (b) in individuals that have a family history of mental disease, and (c) if efficacious, cost-effective, low-risk interventions exist to reduce the risk (Spriggs, Olsson, \& Hall, 2008). At a minimum, we need to weigh the potential benefits in terms of public safety against the risks of stigma, anxiety and unnecessary interventions. According to Shickle and Chadwick (1994), there should be room for a trade-off between the harm that results from screening and early intervention and the harm that is brought about by the failure to screen (and prevent future crime). While we can have legitimate reasons to opt for screening, we can also have legitimate reasons to refrain from screening. A careful assessment of the potential harms of screening versus forgoing to screen is paramount. According to Spriggs et al. (2008), due to the multi-factorial nature of complex behaviors such as violent, anti-social behavior, a greater justification is needed when identifying bio-markers that carry a greater risk in terms of anxiety-inducement and stigmatization (Spriggs et al., 2008).

(3) If a child who has never committed a crime is identified as at-risk to develop deviant, anti-social behavior in later life based on neurobiological screening, who should decide on treatment? Do the parents have decision-making authority or should the child have a veto right? A shared or dual decision-making process creates an environment in which the child's developing autonomy is maximally respected and his/her decision-making skills and agency are nurtured, while enabling the child to benefit from the knowledge that their parents and the expert team provide. It also results in better treatment outcomes and coping. Successful treatment and intervention depends on the individual's willingness to participate and therefore requires the child's involvement in the decisionmaking process.

In general, a number of normative questions need to be addressed on a case-by-case basis before neurobiological tools are implemented: Should parents be persuaded to enroll their at-risk child in a treatment program? Should the government provide incentives for parents to do so? Should child and family services be allowed to ask for neurobiological screening and early intervention? Should schools be allowed to refuse at-risk children who do not enroll in a treatment program?

\subsection{Use of neurobiology to assign (degrees of) responsibility and inform sentencing}

While the current admissibility and reliability of neuroscientific evidence data as evidence in courtrooms is limited and risks of neurodeterminism loom large, neurobiological research may be used in criminal justice settings in a variety of ways. Whether or not we welcome the upcoming era of neurolaw or not, according to some experts, it will be difficult to prevent it from booming: “...there may be a coming tsunami of neurobiological evidence-backed sentencing claims at trial" (Farahany, 2016, 20). Other experts question whether the use of behavioral genetic evidence in courts will continue to grow in the foreseeable future and point to the many challenges that the effective use of such evidence faces (Scurich \& Appelbaum, 2017).

Scientifically valid neuroscience data has the potential to make certain aspects of criminal cases more objective and less prone to subjective interpretation. If the science is reliable, it opens up a range of new opportunities for the law (Greely, 2011). The US Supreme Court has acknowledged on several different occasions that psychiatry is not an exact science and that there exists much dispute and disagreement among different mental health professionals when it comes to diagnoses (Morse, 2011). In trying to establish who satisfies specific psychological demands and who does not, legal decisions easily lend themselves to arbitrary distinctions between individuals that may have profound and unfair consequences. Forensic mental health assessments can be subjective and often differ depending on the forensic expert team in question and their expected role (e.g., court-appointed team versus defense-appointed team).

The Anders Breivik trial in 2012 in Norway provides a well-known example of conflicting expert rapports (Melle, 2013). While the first expert team concluded that Breivik suffers from psychosis, a serious mental health disorder that could result in a 'not legally accountable' verdict by the judge, the second expert team concluded that Breivik did not suffer from psychosis. The second team diagnosed Breivik with narcissistic personality disorder and pathological lying. The latter diagnosis does allow for Breivik to be held legally accountable. Similarly, Belgian Courts rigidly differentiate between individuals who suffer from full-blown mental insanity (e.g., psychosis) and individuals who merely suffer from personality disorders such as schizotypal personality disorder (as assessed by forensic mental health experts) (e.g., Kim De Gelder case, 2013). A diagnosis of schizotypal personality disorder will result in a guilty verdict and a prison sentence whereas schizophrenia will most likely result in a not guilty for reasons of insanity verdict and (indefinite) civil commitment. At the same time, mental health research informs us that schizotypal personality disorder needs to be understood as a precursor to full-blown schizophrenia or as conveying milder symptoms that can be placed on a continuum leading up to full-blown schizophrenia. Where we draw the line between both conditions and why is a normative matter that is prone to subjectivity and uncertainty due to a lack of clear diagnostic features.

According to some experts, neurobiological evidence has the potential to aid in resolving diagnostic disputes and providing a more reliable psychiatric profile (Farahany, 2016; Savitz, Simpson, \& Drevets, 2012; Sirgiovanni et al., 2016). Sirgiovanni et al. (2016) welcome neuroscientific additions to the traditional psychiatric approach of observational DSM-based diagnoses in the legal domain: "The poor quality of data collection and the controversial identification of disorders within the DSM approach is due to the absence of objective measurement procedures combined with DSM's vague and imprecise definition of disorders". Farahany (2016) similarly argues that responsible use of neurobiological evidence has the potential to reduce errors and increase accuracy within the criminal justice system. Specific brain imaging tests and techniques such as diffusion tensor imaging (DTI), structural magnetic resonance imaging (sMRI) and functional magnetic resonance imaging (fMRI) may provide additional information to support or question behavioral diagnoses. For example, whereas dementia used to be diagnosed solely at the behavioral level, brain scans are increasingly used to support clinical characterization and differential diagnosis (Bonifacio \& Zamboni, 2016).

As mentioned under Section 2.1, US Supreme Court cases involving juveniles (Miller v. Alabama and Jackson v. Hobbs) have led to the majority opinion that death sentences and mandatory life sentences without parole for juveniles are unconstitutional. The Court referred to neurobiological studies that indicate that the frontal brain regions of juveniles are not fully developed and make it more difficult for young people to resist crime. The studies suggest that "in the heat of the moment, as in the presence of peers, potential threat, or rewards, emotional centers of the brain hijack less mature prefrontal control circuits during adolescence, leading to poor choice behaviors" (Cohen \& Casey, 2014, 65). Cohen and Casey (2014) conclude that juveniles are fundamentally different from adults and fairness demands that they are sentenced differently.

The question remains however to what extent adult offenders may suffer from similar neurobiological impairments involving suboptimal functioning of prefrontal cognitive-emotional brain regions and networks. Such atypical neurobiological functioning may similarly render these individuals more prone to crime. Neuropsychological research indeed indicates that individuals with severe, impulsive antisocial 
behavior suffer from deficits in 'executive functions' (related to selfcontrol, attention, long-term planning, learning, etc.). Impaired executive functions are associated with less optimal development of or damage to prefrontal brain areas (de Kogel \& Westgeest, 2015). Abnormalities in brain anatomy or functioning that are visible on brain scans may therefore provide additional evidence to support or question a specific behavioral diagnosis in adolescents and adults alike. In fact, some cases may present a rather convincing correlative model, such as the case involving the school teacher who suffered from pedophilic urges due to a (regrown) brain tumor (Burns \& Swerdlow, 2003). Other examples may involve patients with behavioral-variant frontotemporal dementia who develop deviant behavior due to their disease despite being able to explicitly state that their behavior is wrong (Darby, Edersheim, \& Price, 2016).

With regard to current legal systems, it is morally desirable that relevant brain abnormalities are identified and taken seriously. For example, in the Netherlands, it has been estimated that an MRI-scan is made in about half of the criminal cases involving serious offences. The scan is typically combined with expert information from several other disciplines such as neuropsychology, psychiatry and probation services (de Kogel \& Westgeest, 2015). Caution is needed as well. Fuchs (2006) highlights ethical concerns related to our individual rights on privacy, non-interference and inviolability. Brain imaging and other types of neurobiological monitoring could reveal personal information about our identities, our inner thoughts and unconscious attitudes. Fuchs refers to the concept of 'cognitive liberty' as "every person's fundamental right on autonomy over his or her own brain states" (Fuchs, 2006, 602). Bublitz and Merkel (2014) similarly discuss the right to 'mental integrity' and how this may become compromised when faced with brain monitoring and brain interventions. Respect for autonomy and informed consent are therefore crucial to avoid misuse of neurobiological knowledge.

There is very little to no consensus as to what constitutes normal variation in the size of certain brain regions and no independent measure on what constitutes pathology. It is important to recognize that "advances in the neuroscience of mental states do not necessarily mean that associated brain regions are necessary for their normal functioning, and descriptions of abnormal brain activity do not necessarily imply dysfunction" (Edersheim, Weintraub Brendel, \& Price, 2012, 164). Also, "different brains may have different abilities to compensate for pathology" (Edersheim et al., 2012, 164). Moreover, theoretical perspectives influence the methodology and the interpretation of the results. Objectivity is an aspiration and should be the ideal, but this is far from always the case in practice. The same neurobiological evidence can lead either to mitigation or to harsher sentencing depending on the way the evidence is invoked. It can lead to the conclusion that the criminal defendant had less control over his actions due to brain impairments and thus deserves a lesser sentence, or that his brain impairments signal irreversibility and chronic dangerousness and therefore the need for longer sentences or (indefinite) civil commitment.

Some experts raise concerns about the potential for prejudice or undue influence of neurobiological information and brain images on lay persons, mental health experts, judges and jurors, and questions arise on how to avoid neuro-determinism when presented with persuasive brain images (Specker et al., 2017; Weisberg, Keil, Goodstein, Rawson, \& Gray, 2008). It has been argued that neurobiological assessments by experts are sensitive to the 'pathology bias', the 'allegiance effect' and malingering (Merckelbach \& Merckelbach, 2014). Other experts nuance the seductive allure of neuro-images as no inordinate effects are found that go beyond conventional neuroscience expert testimony (Roskies et al., 2013).

Recent studies have found either mitigating, aggravating or no overall impact of neurobiological evidence on culpability and criminal sentencing (Berryessa, 2017; de Kogel \& Westgeest, 2015; Scurich \& Appelbaum, 2016). de Kogel and Westgeest (2015) analyzed published criminal cases in the Netherlands between 2000 and 2012 and found that neuroscientific or behavioral genetic information mitigates accountability assessments in most cases. Recent studies from the United States suggest a null effect regarding the impact of behavioral genetic evidence on criminal sentencing in courts and among lay persons: "Thus, for all the potential that some legal commentators and others have seen in the use of behavioural genetic evidence in support of arguments for diminished responsibility and thus mitigation of punishment, such effects have been difficult to detect in actual cases - with rare exceptions - and are modest or entirely absent in the experimental data" (Berryessa, 2017; Scurich \& Appelbaum, 2017). Scurich and Appelbaum give several possible reasons for these results: (a) biogenetic explanations involve countervailing beliefs, both promoting the idea that individuals with genetic risk factors should be regarded less blameworthy and the idea that individuals with genetic risk factors are more likely to recidivate; (b) lay persons do not comprehend the implications of such findings for behavior and choose to ignore the data, (c) lay persons do not see genes as one of the primary or even a major determinant of behavior and consider such evidence as largely irrelevant to decisions about culpability and punishment, or (d) lay persons and judges alike consider genes as one factor among many factors driving behavior, and claim that this is not incompatible with exercising control over one's behavior.

To maximally avoid misinterpretation and misuse, it is essential that judges, attorneys and other judicial experts are trained to correctly and responsibly interpret neurobiological data if and when it is used within criminal justice settings (Chandler, 2016; Farahany, 2016). Moreover, guidelines and protocols for the use of neuroscientific information in criminal cases "could serve to articulate the state of knowledge, and the ways in which neuroscientific information can and cannot be used" (de Kogel \& Westgeest, 2015, 591). Meynen (2013a) argues that a multidisciplinary team of experts involving lawyers, psychiatrists, ethicists and neuroscientists should asses and identify the "threshold for what can be considered a morally as well as a legally significant impact" of neuroscientific findings on decision-making in order to assist forensic mental health experts assigned to interpret this type of knowledge (Meynen, 2013a, 98). Although each criminal case and the neurobiological information that is gathered needs to be assessed on a case by case basis due to the specificity of each case, such protocols can provide an objective and uniform approach as to how such knowledge should be obtained and interpreted (e.g., about pre-frontal brain damage, about the neurobiology of schizophrenia, about the brain mechanisms involved in sleepwalking), and to what extent such findings impact offenders' decision-making and may therefore be relevant for responsibility assessments. At the same time, it is remains debatable to what extent forensic mental health experts should make claims about (diminished) responsibility, and whether or not such decisions should be made exclusively by judges (Meynen, 2013b, 2016).

\subsection{Neurobiological measures and interventions in forensic mental health}

The importance of accurate diagnostic tools for forensic psychiatry is underscored by the current epidemiological data on the incidence of mental health problems in offenders. In the general population, $2-3 \%$ suffer from antisocial personality disorder and $1 \%$ from psychopathy. In stark contrast, $65 \%$ of male prisoners and $42 \%$ of female prisoners suffer from personality disorders (with $47 \%$ antisocial personality disorder in men and $21 \%$ in women) (Fazel \& Danesh, 2002). More than half of incarcerated individuals suffer from mental health and (comorbid) substance abuse disorders (James \& Glaze, 2006). Moreover, $70 \%-100 \%$ of incarcerated youth suffer from at least one mental health disorder and $20 \%$ suffer from a serious mental health disorder (Odgers, Burnette, Chauhan, Moretti, \& Reppucci, 2005). According to a Swedish population-based study, $1 \%$ of all offenders make up for $63.2 \%$ of all violent crime convictions, and persistent violence was associated with personality disorders, substance abuse disorders and major mental disorders (Falk et al., 2014). Moreover, a large retrospective cohort 
study revealed that offenders with serious psychiatric disorders (major depressive disorder, bipolar disorders, schizophrenia and non-schizophrenic psychotic disorders) have a substantially increased risk of multiple incarcerations over a 6-year follow-up (Baillargeon et al., 2009).

More reliable diagnoses are needed to inform treatment programs and achieve effective rehabilitation. Based on current findings, adequate forensic treatment holds promise to more effectively address recidivism. A systematic review of reoffending rates shows that these are higher for prisoners than for forensic psychiatric patients (for a discussion of UK, US and Swedish studies, see Fazel, Fiminska, Cocks, \& Coid, 2016). Although individual characteristics such as criminal career and seriousness of offences may (partially) explain the difference, it is probable that forensic psychiatric treatment and provision of supportive aftercare contributed to the reduced recidivism. For example, Jeandarme, Habets, Oei, and Bogaerts (2016) found a significant decrease in offences between pre-treatment and post-treatment periods in patients from a medium security forensic hospital, suggesting that forensic psychiatric treatment is effective. A meta-analysis on rehabilitation interventions for offenders with serious psychiatric disorders reports a positive effect of interventions in reducing continued involvement with the criminal justice system (Martin, Dorken, Wamboldt, \& Wootten, 2012). Providing effective treatment and rehabilitation options for prisoners and forensic patients are therefore extremely important.

Despite its obvious shortcomings, the DSM has its merits as a diagnostic tool that allows for interdisciplinary communication and guidance in providing appropriate and effective treatment options. If we consider the risk of false positives inherent to medical diagnoses in general and to psychiatric diagnoses in particular, and the number of individuals within the criminal justice system who suffer from mental illnesses, it could be very valuable to be able to corroborate psychiatric diagnoses based on neuroscientific markers (Wakefield, 2016). For example, there is a growing body of field research that shows that the high reliability and the predictive validity of the PCL-R (Psychopathy Checklist-Revised) in controlled studies does not translate to the field (i.e., in prisons and forensic hospitals, real world settings with real world raters instead of academic researchers) (Jeandarme et al., 2017). As the PCL-R is used both to inform diagnoses and to predict recidivism risk (e.g., a high score may prevent re-entrance in society) these finding are very problematic.

At the same time, biological explanations for mental health disorders and substance abuse disorders may promote false claims of neuro-determinism and potentially undermine successful treatment. Neurobiological explanations "seem to encourage the belief that symptoms are immutable" and may lead to "prognostic pessimism and a reduced sense among patients of personal ability to regulate symptoms, raising the risk of self-fulfilling beliefs in the immutability of mental illness" (Chandler, 2016). Biological explanations increase public perceptions of dangerousness and induce avoidance towards individuals with mental disorders, and may decrease caregivers empathy towards patients (Chandler, 2016). Although the realization that mental health disorders such as schizophrenia, anti-social personality disorder and substance abuse disorders can be understood as brain diseases could help address some of the stigma, blame and discrimination that accompanies these mental health problems, it also has the potential to increase stigma by assuming that these diseases are 'hard-wired' in the brain and therefore difficult to change or overcome. It can increase the false belief that mental disorders are necessarily untreatable or chronic, and that individuals with such disorders are 'dangerous' and should be avoided at all times.

A vignette study found that neurobiological conceptions of mental illness were either unrelated to stigma or increased the likelihood of a stigmatizing reaction, and supporting mixed results were found in similar international studies (see, Pescosolido et al., 2010). Increased awareness concerning the biological correlates of mental illness does appear to increase public support for psychiatric treatment (Angermeyer, van der Auwera, Carta, \& Schomerus, 2017; Pescosolido et al., 2010). Although the public now appears to "reject old etiological notions of individual weakness, secrecy, and moral failure" with respect to mental illnesses, the stigma remains despite increased awareness of the biological correlates of mental illnesses (Pescosolido, Medina, Martin, \& Long, 2013, 857).

Self-stigma decreases the likelihood of help-seeking behavior in individuals experiencing mental health problems. It is considered the primary barrier to mental health treatment and recovery by experts (HHS, 1999), and needs to be avoided and addressed.

"Deeply embedded in social and cultural norms, stigma includes prejudicial attitudes that discredit individuals, marking them as tainted and devalued. For individuals, stigma produces discrimination in employment, housing, medical care, and social relationships. Individuals with mental illness may be subjected to prejudice and discrimination from others (i.e., received stigma), and they may internalize feelings of devaluation (i.e., self-stigma). On a societal level, stigma has been implicated in low service use, inadequate funding for mental health research and treatment (i.e., institutional stigma), and the "courtesy" stigma attached to families, providers, and mental health treatment systems and research." (Pescosolido et al., 2010, 1321-22).

Pickard $(2011,2014)$ has argued that taking responsibility for one's actions may be necessary for the success of therapy as it provides a sense of agency. Individuals may not be able to learn to change their behavior if they and those who work with them do not believe it is in their power to do so. Individuals need to be supported and empowered to make different choices. They need to be seen as responsible agents in order to help them change. While blame and stigma are counterproductive, holding individuals responsible is seen as essential for effective rehabilitation (Pickard, 2017; Pickard \& Pearce, 2013).

Fuchs (2006) expresses concern about the over-application and over-simplification of our concepts of mental illness if we focus too narrowly on the neurobiological aspects of our mental life and behavior, resulting in the medicalization and over-medication of normal behaviors. Atypical brain functioning does not necessarily translate into dysfunctional or problematic behavior, and neuro-reductionist accounts of human behavior negate the causal complexity of mental health problems. Current research suggests that attention for both risk and protective factors is important to achieve effective rehabilitation and recidivism. Much more effort and resources needs to be devoted to enabling offenders to resist future crime, such as investing in practical skills training, education, housing, access to healthcare and employment (Ward, Mann, \& Gannon, 2007). Too much focus on neurobiological impairments and treatments runs the risk of neglecting the systemic causes of crime such as poverty, unemployment, health care inequities and childhood maltreatment, as well as the protective factors that may enable a crime-free life. Exclusively or overly focusing on neurobiological risk factors needs to be avoided.

Forensic psychiatric treatment can be focused on offenders with mental health needs, forensic patients serving a prison sentence, or civilly committed patients in secure forensic treatment centers. Although a combined behavioral and neurobiological approach to deviant antisocial behavior could prove extremely beneficial for the domain of forensic psychiatry and psychology, little to no scientific research studies on neurobiological treatments for offenders are conducted. Hardly any systematic research is available and randomized controlled trials are almost completely absent (Audenaert, Wittouck, \& Berckmoes, 2015; Khalifa et al., 2010; Meynen, 2014; Morgan et al., 2012). Moreover, existing research studies often suffer from methodological shortcomings. According to a 2010 Cochrane systematic review, the evidence base for pharmacological interventions for antisocial personality disorders is weak (Khalifa et al., 2010). A recent follow-up further reveals that not a single pharmacological intervention has been sufficiently tested to merit the label of evidence-based treatment in individuals with antisocial personality disorders and/or psychopathy 
(Audenaert et al., 2015). A limited number of small-scale research studies investigating biological interventions (dietary, tDCS, neurofeedback, etc.) targeting aggressive, hostile and impulsive traits in children and adolescents with conduct disorders and in offenders have recently been published (Audenaert et al., 2015; Dadds et al., 2012; Dean et al., 2014; Wilson, 2015). Several of these studies report promising findings and highlight the need to investigate the effectiveness and safety of neurobiological interventions in forensic psychiatric and offender populations.

When considering the use of neurobiological interventions within the criminal justice system, we need to consider the possibility that disguised attempts at mere behavioral control will flourish under the umbrella of neurobiological rehabilitation. As mentioned, Bublitz and Merkel (2014) argue that all individuals, including offenders, have a right to mental integrity. Such a right is violated if offenders are semicoerced to undergo neuro-interventions that impact their cognitive, affective and motivational capacities. Freedom of thought refers (in part) to our ability to rationally reflect on the many influences that impact us, and our ability to endorse, reject or object to these influences. If proper informed consent is lost, this removes the ability to endorse, reject or object to the psychological and personality changes that are brought about by neuro-interventions (Focquaert \& Schermer, 2015).

Certain forensic patients may benefit from incorporating (new) neurobiological interventions in their treatment program (Audenaert et al., 2015). In fact, offering biomedical treatments under the right circumstances can increase the autonomy and well-being of offenders (Bomann-Larsen, 2013; Caplan, 2006; Douglas, Bonte, Focquaert, Devolder, \& Sterckx, 2013; Focquaert, 2014; Focquaert \& Raine, 2012; Rosati, 1994; Thibaut et al., 2010). Desires, cravings and habits that motivate criminal behavior can be experienced as impediments to making autonomous choices. Neurobiological treatments that reduce the internal coercion that such desires and cravings produce have the potential to increase an individual's autonomy and ability to lead a crime-free life. For example, Caplan (2006) argues that temporarily infringing upon autonomy by offering medical treatment (e.g., naltrexone for drug addiction) can restore and increase autonomy in the long run. Thibaut et al. (2010) similarly argue that androgen deprivation therapy can reduce deviant sexual fantasies or urges (e.g., paraphilic urges).

While mental health disorders and substance abuse disorders can compromise the capacity to be autonomous to varying degrees either acutely, chronic, short term or long term, having a mental health disorder and/or substance abuse disorder does not necessarily imply incompetency or a complete inability to make rational choices: "Very few medical conditions permanently and completely abolish the capacity to make choices, and psychiatry is no exception. Even if patients are detained and have limited choices, mental health professionals have a duty to help service users exercise what autonomy they have and pursue their own choices as best they can" (Adshead \& Davies, 2016, 76). To maximally respect the well-being and dignity of forensic patients, forensic mental health experts should always strive for active cooperation on behalf of forensic patients and maximally respect their remaining autonomy.

Non-invasive neuro-biological interventions may have the potential to ameliorate current approaches to rehabilitation and treatment of deviant behavior. Non-invasive, reversible neuro-interventions include, among others, vitamin and diet supplements, cognitive-emotional training using virtual reality, videogames or neurofeedback, and transcranial magnetic or direct current stimulation. If and when neuro-interventions such as virtual reality therapy, neurofeedback and transcranial direct current stimulation, become part of forensic rehabilitation and treatment programs, the effective use of such neurointerventions will depend on the willingness of the individual or patient in question to participate. Several of these interventions require the active participation of the individual to exert their effects. Moreover, treatment outcomes focusing on changing behavior are usually better when individuals are motivated to undergo treatment (Simpson, Joe, \& Rowan-Szal, 1997).

If such interventions are included in a prevention or treatment program, adequate ethical safeguards need to be in place. At a minimum, forensic experts need to respect the deontological codes and regulations of their profession, which generally include consideration for the prima facie medical ethical principles of autonomy, beneficence ('do good'), non-maleficence ('do no harm') and justice. In forensic mental health settings, these principles necessitate informed consent, adequate respect for an individual's privacy and mental integrity, and concern for the well-being of the individual in question. Concern for the well-being of forensic patients minimally implies that the least invasive option is considered first, that the intervention is psychologically or clinically indicated, and that it offers a good risk-to-benefit ratio in and of itself.

\section{Conclusion}

If neurobiological knowledge can aid in successfully preventing future crime while respecting the rights of all parties involved, including the right to be treated with human dignity and the right to autonomy and mental integrity, both offenders and the wider society can benefit. The biggest gains for neurobiology in the criminal justice systems are most likely to be found in the domains of neurocriminological research and forensic psychiatric treatment and prevention. Gaining knowledge on the neurobiological risk factors for deviant behavior and fine-tuning forensic treatment and rehabilitation to meet those needs, including the development of safe neuro-interventions for therapy-refractory mental health and addiction problems, can result in greater recidivism reduction compared to incarceration without treatment.

One of the most exciting areas where neurobiological measures are useful is the field of criminological research. Research on human aggression and antisocial behavior has largely focused on the societal causes of violent behavior and relatively little on the underlying neurobiological correlates. If we want to increase our understanding of criminal behavior and develop better criminological theories, then we need to incorporate the neurobiological influences on violent, antisocial behavior. If we limit criminological research to the behavioral and environmental aspects underlying such behavior, we are left with a partial understanding of what drives an individual to commit crimes. Neurobiological research therefore provides a valuable additive approach.

When neurobiological knowledge, measures and techniques are used within criminal justice settings, it is recommended that sufficient attention is directed at preventing stigma and neuro-determinism, protecting autonomy, non-interference and mental liberty, and safeguarding privacy. A nuanced and detailed understanding of the ways in which neurobiological markers may or may not influence behavior is needed, and scientists in the field of neurocriminology have the responsibility to disseminate and communicate their findings accordingly. Individuals with mental health and addiction problems are already facing stigma in our society. Adding a neurobiological profile may exacerbate this. Scientists, legal scholars, forensic mental health experts and journalists need to be aware of this and address misinterpretation and misuse of neurobiological findings appropriately.

Although early screening and intervention may benefit some children and adolescents who are at risk of exhibiting violent, anti-social behaviors, there is a substantial risk of increasing anxiety, stigma and unnecessary interventions. Moreover, the stigmatization, internalization and self-blame that results from such labels may stimulate the development of maladaptive cognitions and narratives. While we can have legitimate reasons to opt for screening, we can also have legitimate reasons to refrain from screening. A careful assessment of the potential harms of screening versus forgoing to screen is therefore 


\section{paramount.}

If and when neurobiological knowledge is gathered for detection and prevention purposes, or as part of forensic mental health reports, it is essential that informed consent is obtained to maximally protect an individual's right to autonomy, non-interference, mental liberty and privacy. If and when neuro-interventions are used in forensic mental health settings, the deontological codes of the mental health profession necessitate informed consent, adequate respect for an individual's privacy and mental integrity, and concern for the well-being of the individual in question. The latter minimally implies that the least invasive option is considered first, that the intervention is psychologically or clinically indicated, and that it offers a good risk-to-benefit ratio in and of itself

In the last decades neuroscientific research has contributed significantly to our understanding of human behavior - both with respect to prosocial behavior and deviant, antisocial behavior. Neuroscientists and behavioral geneticists are starting to identify various biological risk factors for (recurrent) violent criminal behavior, including structural and functional brain impairments, genetic variants, hormone and neurotransmitter levels, and physiological indices. Knowledge on the neurobiological determinants of psychopathy and antisocial personality disorder is accumulating across international research labs. Unfortunately, little to no scientific research studies on biomedical treatments for offenders are conducted. If the criminal justice system wishes to benefit from the recent advances in the neurosciences, society should invest more resources in combined behavioral and biomedical rehabilitation and prevention programs for deviant behavior.

\section{References}

Adshead, G., \& Davies, T. (2016). Wise restraints: Ethical issues in the coercion of forensic patients. In B. Völlm, \& N. Nedopil (Eds.). The use of coercive measures in forensic psychiatric care (pp. 69-86). Cham; Switzerland: Springer.

Aharoni, E., Mallett, J., Vincent, G. M., Harenski, C. L., Calhoun, V. D., SinnottArmstrong, W., ... Kiehl, K. A. (2014). Predictive accuracy in the neuroprediction of rearrest. Social Neuroscience, 9(4), 332-336.

Angermeyer, M. C., van der Auwera, S., Carta, M. G., \& Schomerus, G. (2017). Public attitudes towards psychiatry and psychiatric treatment at the beginning of the $21 \mathrm{st}$ century: A systematic review and meta-analysis of population surveys. World Psychiatry, 16, 50-61.

Asherson, P., \& Cormand, B. (2016). The genetics of aggression: Where are we now? American Journal of Medical Genetics Part B: Neuropsychiatric Genetics, 171(5), 559-561.

Audenaert, K., Wittouck, C., \& Berckmoes, A. (2015). Farmacologische en andere medische interventies bij de antisociale persoonlijkheidsstoornis en psychopathie. In W. Canton, D. van Beek, L. Claes, L. Gijs, I. Jeandarme, \& E. Klein Haneveld (Eds.) Handboek psychopathie en de antisociale persoonlijkheidsstoornis (pp. 481-500). Utrecht: De Tijdstroom.

Baillargeon, J., Penn, J. V., Knight, K., Harzke, A. J., Baillargeon, G., \& Becker, E. A. (2009). Risk of reincarceration among prisoners with co-occurring severe mental illness and substance use disorders. Administration and Policy in Mental Health and Mental Health Services Research, 37(4), 367-374.

Balia, C., Carucci, S., Coghill, D., \& Zuddas, A. (2017 Jan 27). The pharmacological treatment of aggression in children and adolescents with conduct disorder. Do callous-unemotional traits modulate the efficacy of medication? Neuroscience and Biobehavioral Reviews, 1-21. (pii: S0149-7634(16)30149-X, Epub ahead of print) https://doi.org/10.1016/j.neubiorev.2017.01.024.

Batista, E. K., Klaus, J., Fregni, F., Nitsche, M. A., \& Nakamura-Palacios, M. N. (2015). A randomized placebo-controlled trial of targeted prefrontal cortex modulation with bilateral tDCS in patients with crack-cocaine dependence. International Journal of Neuropsychopharmacology, 18(12), pyv066. http://dx.doi.org/10.1093/ijnp/pyv066.

Berryessa, C. M. (2017). Jury-eligible public attitudes toward biological risk factors for the development of criminal behavior and implications for capital sentencing. Criminal Justice and Behavior, 44(8), 1073-1100.

Bomann-Larsen, L. (2013). Voluntary rehabilitation? On neurotechnological behavioural treatment, valid consent and (in)appropriate offers. Neuroethics, 6, 65-77.

Bonifacio, G., \& Zamboni, G. (2016). Brain imaging in dementia. Postgraduate Medical Journal, 92, 333-340.

Brown, T., \& Murphy, E. (2010). Through a scanner darkly: Functional neuroimaging as evidence of a criminal defendant's past mental states. Stan. L. Rev. 62, 1119.

Bublitz, J. C., \& Merkel, R. (2014). Crimes against minds: On mental manipulations, harms, and a human right to mental self-determination. Criminal Law and Philosophy, $8,51-77$.

Burns, J. M., \& Swerdlow, R. H. (2003). Right orbitofrontal tumor with pedophilia symptom and constructional apraxia sign. Archives of Neurology, 60, 437-440.

Caplan, A. L. (2006). Ethical issues surrounding forced, mandated, or coerced treatment.
Journal of Substance Abuse Treatment, 31, 117-120.

Caruso, G. D. (2017). Public health and safety: The social determinants of health and criminal behavior. UK: ResearchLinks Books.

Chandler, J. A. (2016). The impact of biological psychiatry on the law: Evidence, blame and social solidarity. Alberta law review. forthcoming; Ottawa Faculty of Law Working Paper No. 2016-27. Available at SSRN: https://ssrn.com/abstract $=2815544$.

Cohen, A. O., \& Casey, B. J. (2014). Rewering juvenile justice: The intersection of developmental neuroscience and legal policy. Trends in Cognitive Sciences, 18(2), 63-65.

Cornet, L. J. M. (2015). Using basic neurobiological measures in criminological research. Crime Science, 4(7).

Cornet, L. J. M., de Kogel, C. H., Nijman, H. L. I., Raine, A., \& van der Laan, P. H. (2015). Neurobiological changes after intervention in individuals with anti-social behaviour. A literature review. Criminal Behaviour and Mental Health, 25, 10-27.

Council of Europe (1997). The convention for the protection of human rights and dignity of the human being with regard to the application of biology and medicine: Convention on human rights and biomedicine (ETS No 164). https://www.coe.int/ en/web/conventions/full-list/-/conventions/treaty/164.

Council for International Organizations of Medical Sciences (CIOMS) in collaboration with the World Health Organization (WHO). (2002). International ethical guidelines for biomedical research involving human subjects. 1-60. https://cioms.ch/wp-content/ uploads/2016/08/International_Ethical_Guidelines_for_Biomedical_Research_ Involving_Human_Subjects.pdf.

Council for International Organizations of Medical Sciences (CIOMS) in collaboration with the World Health Organization (WHO). (2009). International ethical guidelines for epidemiological studies. 1-130. https://cioms.ch/wp-content/uploads/2017/01/ International_Ethical_Guidelines_LR.pdf.

Dadds, M., Cauchi, A. J., Wimalaweera, S., \& Brennan, J. (2012). Outcomes, moderators, and mediators of empathic-emotion recognition training for complex conduct problems in childhood. Psychiatry Research, 199(3), 201-207.

Dambacher, F., Schuhmann, T., Lobbestael, J., Arntz, A., Brugman, S., \& Sack, A. T. (2015). Reducing proactive aggression through non-invasive brain stimulation. SCAN, 10, 1303-1309.

Darby, R. R., Edersheim, J., \& Price, B. H. (2016). What patients with behavioral-variant frontotemporal dementia can teach us about moral responsibility. AJOB Neuroscience, 7(4), 193-201. http://dx.doi.org/10.1080/21507740.2016.1236044.

Dean, A. J., Bor, W., Adam, K., Bowling, F. G., \& Bellgrove, M. A. (2014). A randomized, controlled, crossover trial of fish oil treatment for impulsive aggression in children and adolescents with disruptive behaviour disorders. Journal of Child and Adolescent Psychopharmacology, 24(3), 140-148.

Douglas, T., Bonte, P., Focquaert, F., Devolder, K., \& Sterckx, S. (2013). Coercion, incarceration and chemical castration: An argument from autonomy. Bioethical Inquiry, 10, 393-405.

Edersheim, J. G., Weintraub Brendel, R., \& Price, B. H. (2012). Neuroimaging, diminished capacity and mitigation. In J. R. Simpson (Ed.). Neuroimaging in forensich psychiatryWiley-Blackwell From the clinic to the courtroom.

Elman, I., Borsook, D., \& Volkow, N. D. (2013). Pain and suicidality: Insights from reward and addiction neuroscience. Progress in Neurobiology, 109, 1-27.

Falk, O., Wallinius, M., Lundström, S., Frisell, T., Anckarsäter, H., \& Kerekes, N. (2014). The $1 \%$ of the population accountable for $63 \%$ of all violent crime convictions. Social Psychiatry and Psychiatric Epidemiology, 49, 559-571.

Farah, M. J., Hutchinson, J. B., Phelps, E. A., \& Wagner, A. D. (2014). Functional MRIbased lie detection: Scientific and societal challenge. Nature Reviews Neuroscience, 15, $123-131$.

Farahany, N. A. (2016). Neuroscience and behavioural genetics in US criminal law: An empirical analysis. Journal of Law and the Biosciences, 1-25.

Fazel, S., \& Danesh, J. (2002). Serious mental disorder in 23000 prisoners: A systematic review of 62 surveys. The Lancet, 359(9306), 545-550.

Fazel, S., Fiminska, Z., Cocks, C., \& Coid, J. (2016). Patient outcomes following discharge from secure psychiatric hospitals: A systematic review and meta-analysis. The British Journal of Psychiatry, 208, 17-25.

Felmingham, K., Kemp, A., Williams, L., Das, P., Hughes, G., Peduto, A., \& Bryant, R. (2007). Changes in anterior cingulate and amygdala after cognitive behavior therapy of posttraumatic stress disorder. Psychological Science, 18, 127-129.

Focquaert, F. (2014). Mandatory neurotechnological treatment: Ethical issues. Theoretical Medicine and Bioethics, 35, 59-72.

Focquaert, F., \& Raine, A. (2012). Ethics of community-based sanctions. In S. M. BartonBellessa (Ed.). Encyclopedia of community corrections (pp. 144-148). London: SAGE Reference.

Focquaert, F., \& Schermer, M. (2015). Moral enhancement: Do means matter morally? Neuroethics, 8, 139-159.

Fuchs, T. (2006). Ethical issues in neuroscience. Current Opinion in Psychiatry, 600-607.

Glenn, A. L., Focquaert, F., \& Raine, A. (2015). Prediction of antisocial behavior. Review and ethical issues. In J. Clausen, \& N. Levy (Eds.). Handbook of neuroethics (pp. 16891701). Springer.

Glenn, A. L., \& Raine, A. (2014). Neurocriminology: Implications for the punishment, prediction and prevention of criminal behaviour. Nature Reviews Neuroscience, 15 54-63.

Glenn, A. L., Raine, A., \& Schug, R. A. (2009). The neural correlates of moral decisionmaking in psychopathy. Molecular Psychiatry, 14, 5-6.

Glenn, A. L., Schug, R. A., Gao, Y., \& Granger, D. A. (2011). Increased testosterone-tocortisol ratio in psychopathy. Journal of Abnormal Psychology, 120, 389-399.

Greely, H. T. (2011). Reading minds with neuroscience: Possibilities for the law. Cortex, 47, 1254-1255.

Holm, S. (2007). Obesity interventions and ethics. Obesity Reviews, 8, 207-210.

Hörskotter, D., Berghmans, R., \& de Wert, G. (2014). Early prevention of antisocial behavior (ASB): A comparative ethical analysis of psychosocial and biomedical 
approaches. BioSocieties, 9(1), 60-83.

James, D. J., \& Glaze, L. E. (2006). Mental health problems of prison and jail inmates. Special Report Bureau of Justice Statistics. U.S. Department of Justice.

Jeandarme, I., Edens, J., Habets, P., Bruckers, L., Oei, T. I., \& Bogaerts, S. (2017). PCL-R field validity in prison and hospital settings. Law and Human Behavior, 41(1), 29-43.

Jeandarme, I., Habets, P., Oei, T. T., \& Bogaerts, S. (2016). Reconviction and revocation rates in Flanders after medium security treatment. International Journal of Law and Psychiatry, 47, 45-52.

Khalifa, N., Duggan, C., Stoffers, J., Huband, N., Völlm, B. A., Ferriter, M., \& Lieb, K. (2010). Pharmacological interventions for antisocial personality disorder. Cochrane Database of Systematic Reviews, 8, CD007667.

de Kogel, C. H., \& Westgeest, E. J. M. C. (2015). Neuroscientific and behavioral genetic information in criminal cases in the Netherlands. Journal of Law and the Biosciences, 23(2), 580-605.

Konicar, L., Veit, R., Eisenbarth, H., Barth, B., Tonin, P., Strehl, U., \& Birbaumer, N. (2015). Brain self-regulation in criminal psychopaths. Scientific Reports, 5(9426).

Livesly, J. W. (2012). Disorder in the proposed DSM-5 classification of personality disorders. Clinical Psychology \& Psychotherapy, 19, 364-368.

Martin, M. S., Dorken, S. K., Wamboldt, A. D., \& Wootten, S. E. (2012). Stopping the revolving door: A meta-analysis on the effectiveness of interventions for criminally involved individuals with major mental disorders. Law and Human Behavior, 36(1), $1-12$.

Melle, I. (2013). The Breivik case and what psychiatrists can learn from it. World Psychiatry, 12, 16-21.

Merckelbach, H. L. G. J., \& Merckelbach, S. E. M. (2014). Neurobewijs in de rechtszaal? Eerst een protocol. Nederlands Tijdschrift voor Geneeskunde, 158(A7020), 1-3.

Meynen, G. (2013a). A neurolaw perspective on psychiatric assessments of criminal responsibility: Decision-making, mental disorder and the brain. International Journal of Law and Psychiatry, 36, 93-99.

Meynen, G. (2013b). De psychiater en toerekeningsvatbaarheid. Justitiële Verkenningen, 39(1), 54-64.

Meynen, G. (2014). Neurolaw: Its relevance for forensic psychiatry. Tijdschrift voor Psychiatrie, 56, 597-604.

Meynen, G. (2016). Legal insanity: Explorations in psychiatry, law and ethics. Springer.

Micoulaud-Franchi, J. A., Geoffroy, P. A., Fond, G., Lopez, R., Bioulac, S., \& Philip, P. (2014). EEG neurofeedback treatments in children with ADHD: An updated metaanalysis of randomized controlled trials. Frontiers in Human Neuroscience, 8, 906. http://dx.doi.org/10.3389/fnhum.2014.00906.

Morgan, R. D., Flora, D. B., Kroner, D. G., Mills, J. F., Varghese, F., \& Steffan, J. S. (2012). Treating offenders with mental illness: A research synthesis. Law and Human Behavior, 36(1), 37-50.

Moriarty, J. C. (2008). Flickering admissibility: Neuroimaging evidence in U.S. courts. Behavioral Sciences \& the Law, 26, 29-49.

Morse, S. J. (2011). Mental disorder and criminal law. The Journal of Criminal Law and Criminology, 101, 885-968.

Nee, C., \& Vernham, Z. (2017). Expertise and its contribution to the notion of protective factors in offender rehabilitation and desistance. Aggression and Violent Behavior, 32, $37-44$.

Odgers, C. L., Burnette, M. L., Chauhan, P., Moretti, M. L., \& Reppucci, D. (2005). Misdiagnosing the problem: Mental health profiles of incarcerated juveniles. The Canadian child and Adolescent Psychiatry Review, 14(1), 26-29.

O'Leary, M. M., Taylor, J., \& Eckel, L. A. (2010). Psychopathic personality traits and cortisol response to stress: The role of sex, type of stressor, and menstrual phase. Hormones and Behavior, 58, 250-256.

Paquette, V., Levesque, J., Mensour, B., Leroux, J. M., Beaudoin, G., Bourgouin, P., \& Beauregard, M. (2003). "Change the mind and you change the brain": Effects of cognitive-behavioral therapy on the neural correlates of spider phobia. NeuroImage, 18, 401-409.

Pescosolido, B. A., Martin, J. K., Long, J. S., Medina, T. R., Phelan, J. C., \& Link, B. G. (2010). "A disease like any other"? A decade of change in public reactions to schizophrenia, depression, and alcohol dependence. American Journal of Psychiatry, 167, 1321-1330.

Pescosolido, B. A., Medina, T. R., Martin, J. K., \& Long, J. S. (2013). The "backbone" of stigma: Identifying the global core of public prejudice associated with mental illness. American Journal of Public Health, 103, 853-860.

Pickard, H. (2011). Responsibility without blame: Empathy and the effective treatment of personality disorder. Philosophy, Psychiatry, Psychology, 18, 209-224.

Pickard, H. (2014). Responsibility without blame: Therapy, philosophy, law. Prison Service Journal, 213, 10-16.

Pickard, H. (2017). Responsibility without blame for addiction. Neuroethics, 10(1), 169-180. online first https://doi.org/10.1007/s12152-016-9295-2.

Pickard, H., \& Pearce, S. (2013). Addiction in context. Philosophical lessons from a personality disorder clinic. In N. Levy (Ed.). Addiction and self-control: Perspectives from philosophy, psychology and neuroscience (pp. 165-194). Oxford University Press.

Raine, A. (2013). The anatomy of violence: The biological roots of crime. Pantheon.

Raine, A., Portnoy, J., Liu, J., Mahoomed, T., \& Hibbeln, J. R. (2015). Reduction in behavior problems with omega-3 supplementation in children aged 8-16 years: A randomized, double-blind, placebo-controlled, stratified, parallel-group trial. Journal of Child Psychology and Psychiatry, 56(5), 509-520.

Rosati, C. S. (1994). A study of internal punishment. Wisconsin Law Review, 123, 123-170.

Roskies, A., Schweitzer, N. J., \& Saks, M. J. (2013). Neuroimages in court: Less biasing than feared. Trends in Cognitive Sciences, 17(3), 99-101.

Ruedo, M. R., Posner, M. I., \& Rothbart, M. K. (2005). The development of executive attention: Contributions to the emergence of self-regulation. Developmental Neurospychology, 28(2), 573-594.

Sadler, J. Z. (2013). Vice and mental disorders. In K. W. M. Fulford, (Ed.). The Oxford handbook of philosophy and psychiatry. Oxford University Press.

Savitz, J. B., Simpson, J. R., \& Drevets, W. C. (2012). Neuro-imaging in affective disorders: Applications in clinical research and forensic psychiatry. In J. R. Simpson (Ed.). Neuroimaging in forensich psychiatryWiley-Blackwell From the clinic to the courtroom.

Scotto Rosato, N., Correll, C. U., Pappadopulos, E., Chait, A., Crystal, S., Jensen, P. S., \& on behalf of the Treatment of Maladaptive Aggressive in Youth Steering Committee (2012). Treatment of maladaptive aggression in youth: CERT guidelines II: Treatments and ongoing management. Pediatrics, 129(6), e1577-1586.

Scurich, N., \& Appelbaum, P. S. (2016). The blunt-edged sword: Genetic explanations of misbehavior neither mitigate nor aggravate punishment. Journal of Law and the Biosciences, 3(1), 140-157.

Scurich, N., \& Appelbaum, P. S. (2017). Behavioural genetics in criminal court. Nature Human Behavior, 1, 772-774. online first https://doi.org/10.1038/s41562-0170212-4.

Shickle, D., \& Chadwick, R. (1994). The ethics of screening: Is 'screeningitis' an incurable disease? Journal of Medical Ethics, 20(1), 12-18.

Simpson, D. D., Joe, G. W., \& Rowan-Szal, G. A. (1997). Drug abuse treatment retention and process effects on follow-up outcomes. Drug and Alcohol Dependence, 47(3), 227-235.

Sirgiovanni, E., Corbellini, G., \& Caporale, C. (2016). A recap on Italian neurolaw: Epistemological and ethical issues. Mind \& Society, 1-19. online first https://doi.org/ 10.1007/s11299-016-0188-1.

Sitaram, R., Caria, A., Veit, R., Gaber, T., Ruiz, S., \& Birbaumer, N. (2014). Volitional control of the anterior insula in criminal psychopaths using real-time fMRI neurofeedback: A pilot study. Frontiers in Behavioral Neuroscience, 8(344).

Soff, C., Sotnikova, A., Christiansen, H., Becker, K., \& Siniatchkin, M. (2017). Transcranial direct current stimulation improves clinical symptoms in adolescents with attention deficit hyperactivity disorder. Psychiatry and Preclinical Psychiatric Studies, 124, 133-144.

Specker, J., Focquaert, F., Raus, K., Sterckx, S., \& Schermer, M. (2014). The ethical desirability of moral bioenhancement: A review of reasons. BMC Medical Ethics, 15(67).

Specker, J., Focquaert, F., Sterckx, S., \& Schermer, M. (2017). Forensic practitioners' expectations and moral views regarding neurobiological interventions in offenders with mental disorders. BioSocieties, 1-18. http://dx.doi.org/10.1057/s41292-0170069-9.

Spriggs, M., Olsson, C. A., \& Hall, W. (2008). How will information about the genetic risk of mental disorders impact on stigma? The Australian and New Zealand Journal of Psychiatry, 42(3), 214-220. http://dx.doi.org/10.1080/00048670701827226.

Steinberg, L. (2013). The influence of neuroscience on US Supreme Court decisions about adolescents' criminal culpability. Nature Reviews Neuroscience, 14, 513-518.

Thibaut, F., De La Barra, F., Gordon, H., Cosyns, P., Bradford, J. M. W., \& the WFSBP Task Force on Sexual Disorders (2010). The World Federation of Societies of Biological Psychiatry (WFSBP) guidelines for the biological treatment of paraphilias. World Journal of Biological Psychiatry, 11, 604-655.

US Department of Health and Human Services (HHS) (1999). Mental health: A report of the surgeon general. Bethesda, Maryland: US Department of Health and Human Services.

Volkow, N. D., \& Baler, R. D. (2014). Addiction science: Uncovering neurobiological complexity. Neuropharmacology, 76, 235-249.

Wakefield, J. C. (2016). Diagnostic issues and controversies in DSM-5: Return of the false positives problem. Annual Review of Clinical Psychology, 12, 16.1-16.28.

Ward, T., Mann, R. E., \& Gannon, T. A. (2007). The good lives model of offender rehabilitation: Clinical implications. Aggression and Violent Behavior, 12, 87-107.

Weisberg, D. S., Keil, F. C., Goodstein, J., Rawson, E., \& Gray, J. R. (2008). The seductive allure of neuroscience explanations. Journal of Cognitive Neuroscience, 20(3), 470-477.

Widiger, T. A. (2011). The DSM-5 dimensional model of personality disorder: Rationale and empirical support. Journal of Personality Disorders, 25, 222-234.

Wilson, S. J. (Ed.). (2015). The Wiley handbook on the cognitive neuroscience of addiction. Chichester, UK: Wiley Blackwell.

World Medical Association Declaration of Helsinki (2013). Ethical principles for medical research involving human subjects. Journal of the American Medical Association, 310(20), 2191-2194.

Yang, Y., \& Raine, A. (2009). Prefrontal structural and functional brain imaging findings in antisocial, violent, and psychopathic individuals: A meta-analysis. Psychiatry Research, 174, 81-88. 